\title{
Clinical Value of the Carotid Ultrasound in Evaluation of Plaque Composition as Compared to the Carotid MRI
}

\author{
AHMED S. ABDELRAHMAN, M.D. and HAZEM I. KORASHI, M.D. \\ The Department of Radiology, Faculty of Medicine, Ain Shams University
}

\begin{abstract}
Background: The main aim of carotid imaging studies is the assessment of the carotid plaque morphology with the detection of vulnerable plaques which is associated with increased risk of cerebrovascular insult, hence proper delineation of plaque composition is a crucial step for further management of brain ischemic insult.
\end{abstract}

Aim of Study: To define the inter method agreement between the carotid ultrasound and carotid MRI for characterization of vulnerable plaques with further assessment of carotid ultrasound sensitivity and specificity.

Material and Methods: The study was conducted over 60 patients. The modified G-W classification was used to assess the sonographic features of the carotid plaques, and compared with the plaque composition using carotid MRI.

Results: Our study included 60 patients, their ages ranged between 53 and 78 years with a mean age of $60.3 \pm 9.8$ years $56.7 \%$ of patients was male. The agreement between carotid ultrasound and carotid MRI was good with $\kappa=0.734$, sensitivity of the carotid ultrasound to detect the vulnerable plaque was $88.1 \%$ with an overall accuracy of $88.3 \%$.

Conclusion: The carotid ultrasound examination is considered the first-line modality for assessment of the carotid plaque composition, with good agreement with carotid MRI and acceptable sensitivity and accuracy for characterization of vulnerable plaques.

Key Words: Magnetic Resonance Image (MRI) - Ultrasound $(U S)$ - Proton Density $(P D)$ - Time of Flight (TOF).

\section{Introduction}

ISCHEMIC cerebrovascular disease is a major cause of mortality and morbidity all over the world, and the further management of ischemic cerebrovascular disease depends upon the noninvasive assessment of the carotid plaques especially the plaque composition as well as the intimal wall thickness [1].

Correspondence to: Dr. Ahmed S. Abdelrahman, E-Mail: dr ahmedsamy@yahoo.com
Although, the degree of carotid artery stenosis is a fundamental parameter in deciding which patient may benefit from treatment of carotid lesion, yet a large proportion of cerebral insults may be caused by thromboembolism, and the degree of carotid artery stenosis does not always predict those patients who can develop vulnerable lesions, as small vulnerable plaque may also predispose to cerebrovascular events [2]

Several studies comparing the symptomatic and asymptomatic atherosclerotic plaques in relation to the plaque characteristics have been demonstrated that vulnerable plaque was associated with ischemic brain insult [3].

The primary clinical objective of carotid imaging is to improve the ability to identify the atherosclerotic plaques especially the unstable vulnerable one which is associated with increased risk of thromboembolic events, hence the imaging of carotid plaques can help in monitoring the response of lipid-lowering therapy [4].

Imaging of the extra-cranial carotid system by carotid ultrasound and duplex is a good screening technique [5]. The new advancement in the MRI radiofrequency coil and pulse sequence have resulted in high MRI spatial-resolution, witch in addition to high MRI reproducibility, has allowed detailed evaluation of carotid wall and plaque morphology [6,7].

The aim of this study was to assess the agreement between carotid ultrasound and carotid MRI in the assessment of the plaque composition and to evaluate the diagnostic performance of carotid ultrasound as compared to carotid MRI, in addition to evaluation of the risk factor of carotid atherosclerotic disease. 


\section{Material and Methods}

\section{Patients:}

This prospective study was conducted over 60 patients referred to the Radiology Department, Ain Shams University Hospital and other private centers from either outpatient clinic or from the Neurology Department. The mean age of our study patients was $60.3 \pm 9.8$ years (range between 53 and 78 years). The study was performed from September 2017 to June 2018. According to rule of ethical committee, an informed written consent was taken from each patient or their relative prior to the study.

\section{Inclusion criteria:}

- Patients with carotid plaque diagnosed by carotid ultrasound examination.

- No age or sex predilection.

\section{Exclusion criteria:}

- Irritable patients to the degree that interfere with adequate image acquisition.

- MRI contraindications e.g. claustrophobia, cardiac pacemaker, and others.

- Patients underwent carotid artery stenting.

Study tools:

After taking a detailed history from all patients, carotid ultrasound and duplex examination was done for all patient, then the MRI examination of the carotid system was done on the same day.

\section{Carotid ultrasound and duplex technique:}

Patients laid in supine position with their neck extended, and the carotid ultrasound assessment was carried out using (LOGIQTM P7, GE Healthcare) ultrasound machine, all carotid vessels was examined in both transverse and longitudinal planes and representative gray-scale and color images of all vessels obtained using a high-frequency linear probe $(7-10 \mathrm{MHz})$.

\section{MRI technique:}

An MRI of the extracranial carotid arteries was done for all patients using a 1.5-Tesla superconductive magnet (Philips Achieva scan) and SENSE neurovascular coil. The following Fast Spin Echo (FSE) axial sequences were obtained; T1 WI, T2 WI, PD and 3D TOF (Table 1).

\section{Data interpretation:}

The sonographic feature of each plaque in the Carotid ultrasound examination was described using the modified Gray-Weale (G-W) classification [8], which classify plaque as type 1 plaque (uniformly anechoic or hypoechoic), Type 2 (predominantly (>50\%) hypoechoic), Type 3 (predominantly (>50\%) hyperechoic), Type 4 (uniformly hyperechoic) and Type 5 (calcified plaque; posterior shadowing behind uniformly echogenic plaque). The type I and II plaques were referred to as "vulnerable plaques", while other types were referred to as stable plaque [8]

The internal component of the plaque either lipid, hemorrhage, calcification, or fibrous tissues were described based on the MR signal intensities of the carotid plaque (Table 2) [9].

Table (1): Parameter of MRI of extracranial carotid arteries.

\begin{tabular}{lllll}
\hline Sequence & T1WI & T2WI & PD & \multirow{2}{*}{ 3D TOF } \\
& FSE & FSE & FSE & \\
\hline Slices & 16 & 16 & 16 & 48 in 1 slab \\
Slice thickness & 3 & 3 & 3 & 1 \\
Phase encoding & A >P & A >P & A >P & R > L \\
FOV reading $(\mathrm{mm})$ & 80 & 80 & 80 & 114 \\
TR (ms) & 1110 & 2870 & 2750 & 30 \\
TE (ms) & 8.8 & 60 & 12 & 7.3 \\
Flip angle degree & 180 & 180 & 120 & 25 \\
\hline
\end{tabular}

Table (2): Signal intensity of the carotid plaque components on MRI.

\begin{tabular}{lllll}
\hline $\begin{array}{l}\text { Plaque } \\
\text { component }\end{array}$ & T1 WI & T2 WI & \multicolumn{2}{c}{ Proton 3D TOF } \\
density & image \\
\hline Lipid core & $\bullet$ Iso/hyper & $\bullet$ Hypo & $\bullet$ Iso/hyper & $\bullet$ Iso \\
Fibrous tissue & $\bullet$ Iso/hyper & $\bullet$ Iso/hyper & $\bullet$ Iso/hyper & $\bullet$ Iso \\
Hemorrhage & $\bullet$ Hyper & $\bullet$ Variable & $\bullet$ Variable & $\bullet$ Hyper \\
Calcification & $\bullet$ Marked & $\bullet$ Marked & $\bullet$ Marked & $\bullet$ Marked \\
& hypo & hypo & hypo & hypo \\
\hline
\end{tabular}

Statistical analysis:

The data was collected then analyzed using the Statistical Package for Social Science (IBM SPSS) version 22. An inter method agreement between both examination tools was examined using Cohen's kappa coefficient $(\kappa)$. The parametric quantitative data were presented as ranges and mean with standard deviations, while the qualitative data was presented as numbers and percentages. The Receiver Operating Characteristic curve (ROC) was used to assess the sensitivity and accuracy of ultrasound compared to the MRI results. A $p$-value $<0.05$ was considered a statistically significant $p$-value.

\section{Results}

Our study included 60 patients, their ages ranged was between 53 years and 78 years with a mean age of $60.3 \pm 9.8$ years. Thirty-four patients were male $(56.7 \%)$ and twenty-six patients were female (43.3\%) of the cases. No significant difference noted between the different types of carotid plaques 
and the patient age or sex ( $p$-value 0.69 and 0.78 respectively).

The predominant type of atherosclerotic carotid plaque in the carotid ultrasound duplex examination was the vulnerable plaques which was displayed in 39 cases $(65 \%)$ as type 1 plaque was seen in 29 cases $(48.3 \%)$ and type 2 plaque was detected in 10 cases $(16.7 \%)$, yet the stable plaque was expressed in 21 cases (35\%) as type 3 plaque was demonstrated in 3 cases (5\%), type 4 plaque was visualized in 9 cases $(15 \%)$, and type 5 calcific plaque was revealed in 9 cases $(15 \%)$ (Table 3 ).

The more frequent type of the carotid plaque in the extracranial carotid MRI examination was also the vulnerable plaques as they were noted in 42 cases $(70 \%)$ expressed by lipid-rich and hemorrhagic plaques which were revealed in 13 (21.7\%) and $29(48.3 \%)$ cases respectively while stable plaques was demonstrated in 18 cases (30\%), and it included the fibrotic and calcific plaques which were detected in $8(13.3 \%)$ and $10(16.7 \%)$ cases respectively (Table 4 ).

A good inter-method agreement was resolved between the carotid ultrasound and the carotid MRI examinations for the characterization of carotid vulnerable plaque $(\mathrm{ic}=0.734, p<0.001)$ Figs. (1-3).

A slight agreement was noted between the vulnerable plaque (type 1 and 2 plaque) detected by the carotid ultrasound and the lipid-rich plaque detected by the carotid MRI ( $\mathrm{x}=0.087, p<0.04)$, while there was a moderate agreement between the type 1 and type 2 plaques resolved in the carotid ultrasound and the hemorrhagic plaque detected by the carotid MRI $(\kappa=0.536, p<0.001)$.

The analysis of MRI vulnerable plaque revealed that 10 out of 13 (76.9\%) of the lipid-rich plaque was detected by the carotid ultrasound examination as type I or type II plaque, and there were three false-negative cases, while $27(93.1 \%)$ of the hemorrhagic plaque detected by the carotid MRI was correctly classified as type 1 or type 2 vulnerable plaque in the carotid ultrasound examination with two plaques was falsely diagnosed by the carotid ultrasound examination, giving a highly significant value for the hemorrhagic plaques $(p$-value $=0.009)$ (Table 5).

37 out of $42(88.1 \%)$ of the MRI vulnerable plaque (lipid and hemorrhagic plaques) was detected in the carotid ultrasound examination (type 1 and type 2$)(p=0.029)$ (Table 6$)$, the sensitivity and specificity of the carotid duplex to detect the vulnerable plaque was $88.1 \%$ and $88.8 \%$ respectively, with diagnostic accuracy of $88.3 \%$.

A significant correlation between diabetes and dyslipidemia as risk factors and the presence of vulnerable plaque, as $86 \%$ of patient suffering from vulnerable plaque was diabetic and $92 \%$ of them was suffering from dyslipidemia $(p$-value $=$ 0.007 and 0.006 respectively). $81 \%$ of patient diagnosed with vulnerable plaque was presented with neurological manifestation as a presenting symptom $(p$-value $=0.008)$ (Table 7).

Table (3): The morphology of the carotid plaque by the carotid ultrasound.

\begin{tabular}{lll}
\hline Carotid Ultrasound examination & No. & $\%$ \\
\hline Type 1 plaque & 29 & 48.3 \\
Type 2 plaque & 10 & 16.7 \\
Type 3 plaque & 3 & 5 \\
Type 4 plaque & 9 & 15 \\
Type 5 plaque & 9 & 15 \\
\hline
\end{tabular}

Table (4): The morphology of the carotid plaque by the carotid MRI.

\begin{tabular}{lcc}
\hline Carotid MRI examination & No. & $\%$ \\
\hline Lipid plaque & 13 & 21.7 \\
Hemorrhagic plaque & 29 & 48.3 \\
Calcific plaque & 10 & 16.7 \\
Fibrotic plaque & 8 & 13.3 \\
\hline
\end{tabular}

Table (5): Comparison between carotid ultrasound and carotid MRI as regards the morphology of the plaque.

\begin{tabular}{lcccc}
\hline \multicolumn{1}{c}{ MRI $(\mathrm{No}=60)$} & $\begin{array}{c}\text { Lipid } \\
(\mathrm{No}=13) \\
\text { Carotid }\end{array}$ & $\begin{array}{c}\text { Hemorrhagic } \\
(\mathrm{No}=29) \\
\text { No. }\end{array}$ & $\begin{array}{c}\text { Calcific } \\
(\mathrm{No}=10) \\
\text { No. }\end{array}$ & $\begin{array}{c}\text { Fibrotic } \\
(\mathrm{No}=8) \\
\text { No. }\end{array}$ \\
\hline Type 1 $(\mathrm{No}=29)$ Positive & 7 & 20 & 0 & 2 \\
Type 2 $(\mathrm{No}=10)$ Positive & 3 & 7 & 0 & 0 \\
Type 3 $(\mathrm{No}=3)$ Positive & 2 & 1 & 0 & 1 \\
Type 4 $(\mathrm{No}=9)$ Positive & 1 & 1 & 2 & 4 \\
Type 5 $(\mathrm{No}=9)$ Positive & 0 & 0 & 8 & 1 \\
\hline
\end{tabular}


Table (6): The sensitivity, specificity, and accuracy of the carotid ultrasound to detect the vulnerable and stable plaques.

\begin{tabular}{lccccccc}
\hline \multirow{2}{*}{ Ultrasound } & \multicolumn{2}{c}{ MRI } & Sens. & Spec. & PPV & NPV & $p$-value \\
\cline { 2 - 6 } & Vulnerable $(\mathrm{No}=42)$ & Stable $(\mathrm{No}=18)$ & & & & & \\
\hline Vulnerable $(\mathrm{No}=39)$ & $\mathrm{TP}=37$ & $\mathrm{FP}=2$ & $88.1 \%$ & $88.8 \%$ & $94.8 \%$ & $76.2 \%$ & 0.029 \\
Stable $(\mathrm{No}=21)$ & $\mathrm{FN}=5$ & $\mathrm{TN}=16$ & & & & & \\
\hline
\end{tabular}

Table (7): Relation between type of plaque by carotid ultrasound, the risk factors, and clinical consequences.

\begin{tabular}{|c|c|c|c|c|c|c|}
\hline \multirow{2}{*}{ Risk factor } & \multicolumn{2}{|c|}{$\begin{array}{l}\text { Vulnerable plaques } \\
\qquad(\mathrm{No}=42)\end{array}$} & \multicolumn{2}{|c|}{$\begin{array}{l}\text { Stable plaques } \\
\quad(\mathrm{No}=18)\end{array}$} & \multirow[t]{2}{*}{$p$-value } & \multirow[t]{2}{*}{ Sig. } \\
\hline & No. & $\%$ & No. & $\%$ & & \\
\hline Diabetes mellitus & 36 & 86 & 6 & 33 & 0.007 & HS \\
\hline Dyslipidemia & 39 & 92 & 5 & 28 & 0.006 & HS \\
\hline Hypertension & 19 & 45 & 11 & 61 & 0.798 & NS \\
\hline Neurological manifestations & 34 & 81 & 5 & 28 & 0.008 & HS \\
\hline
\end{tabular}

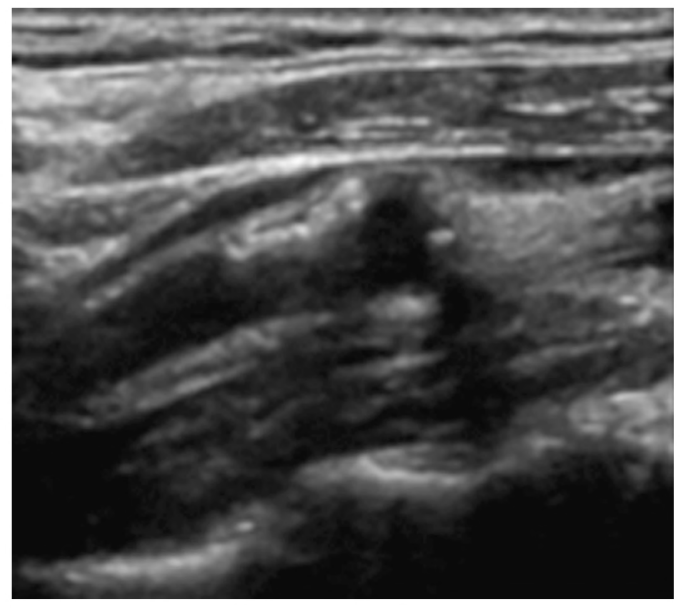

(A)

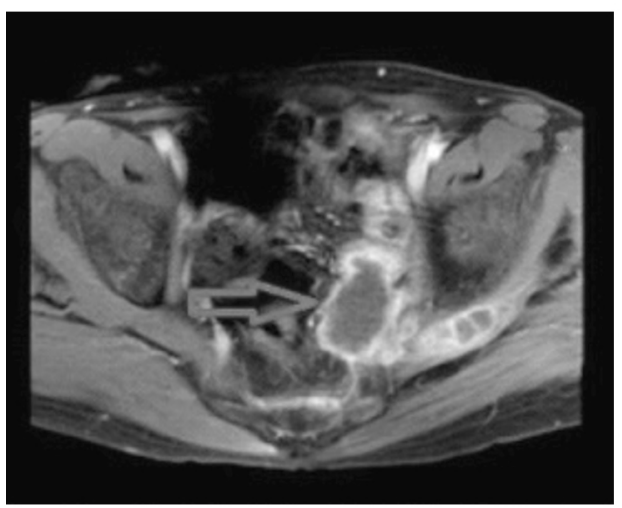

(C)

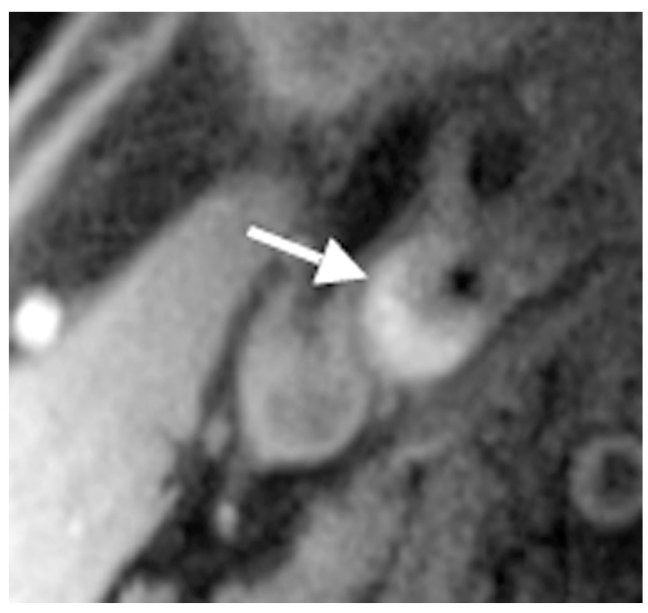

(B)

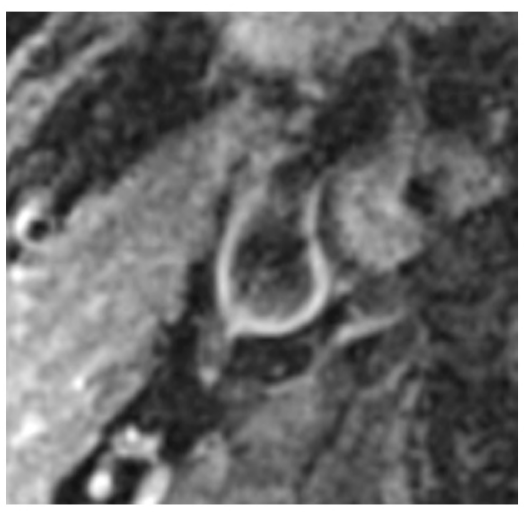

(D)

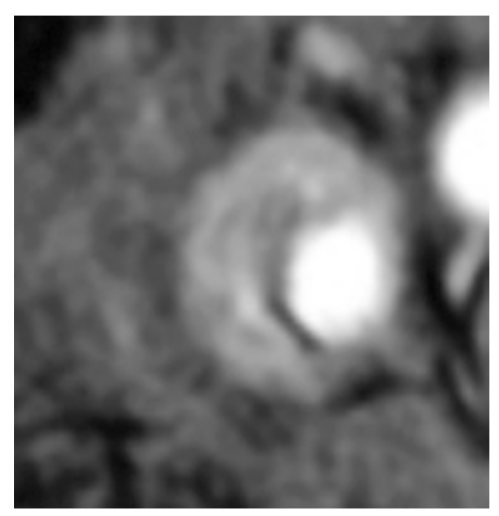

(E)

Fig. (1): A 61 years old male patient, diabetic for 10 years, and presented with attacks of dysarthria. (A) By carotid US duplex: Type 4 carotid plaque is noted in the anterior wall of the right ICA. (B, C, D, E). By MRI: Right ICA shows hyperintense plaque in all pulse sequences (arrow) suggestive of hemorrhage, final MR diagnosis: Hemorrhagic plaque. 


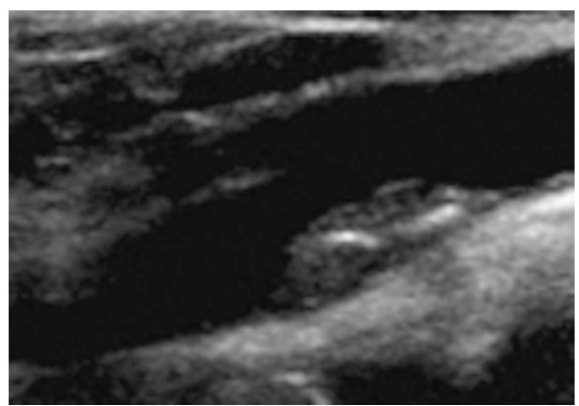

(A)

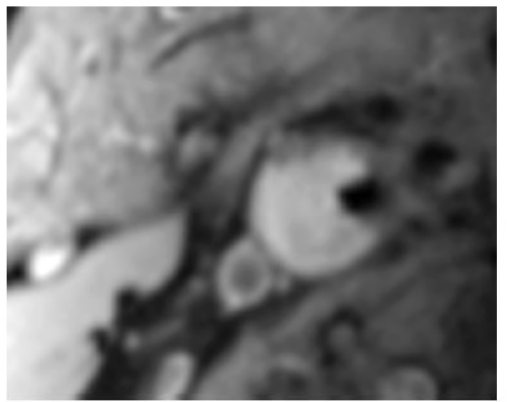

(D)

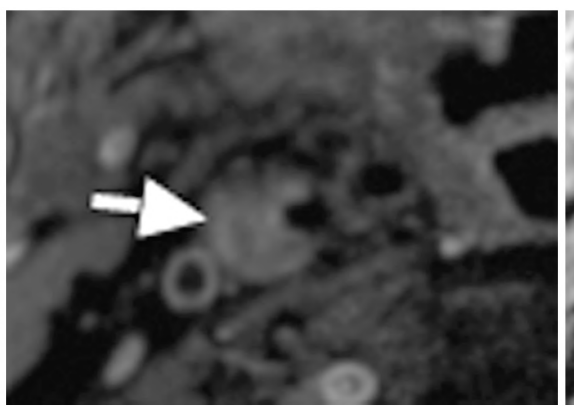

(B)

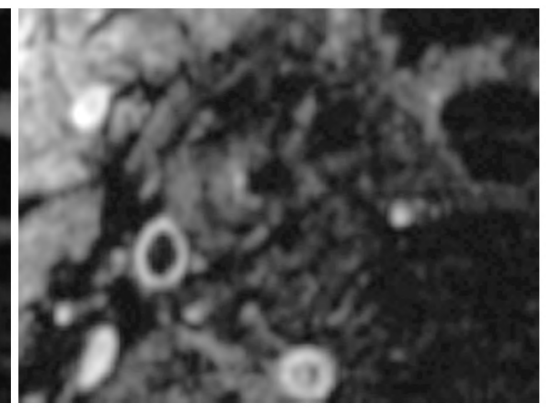

(C)

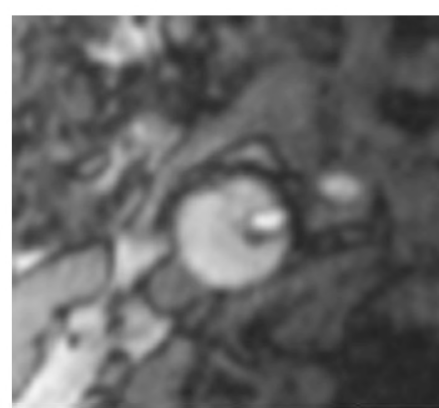

(E)

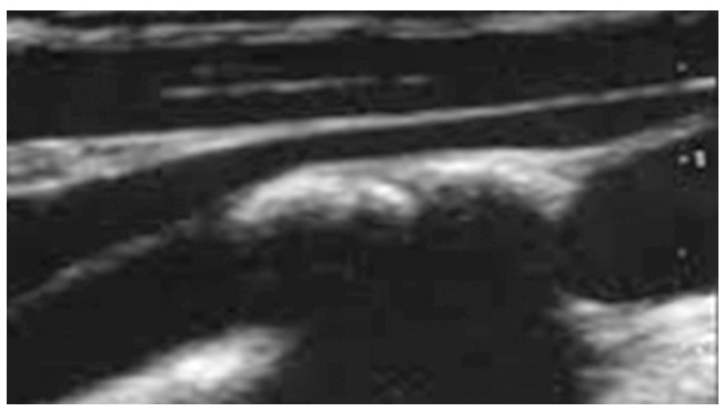

(A)

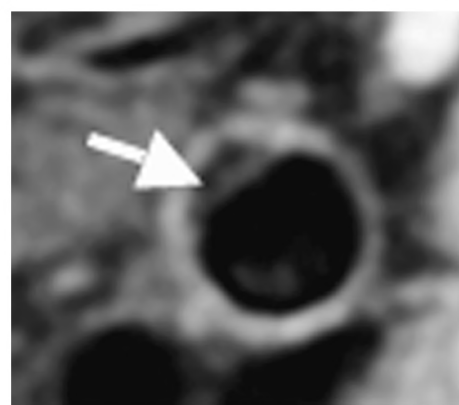

(B)

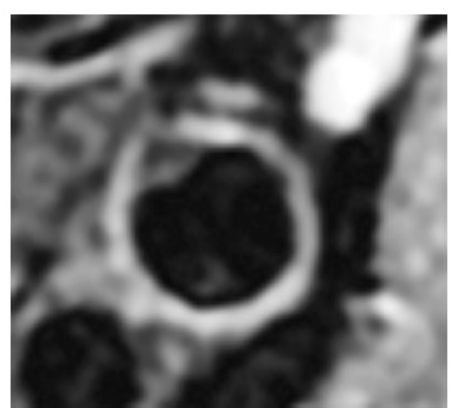

(C)

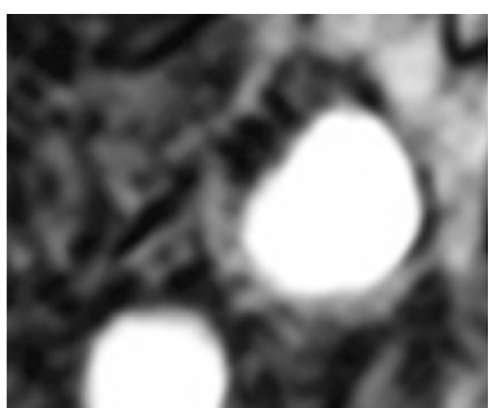

(D)

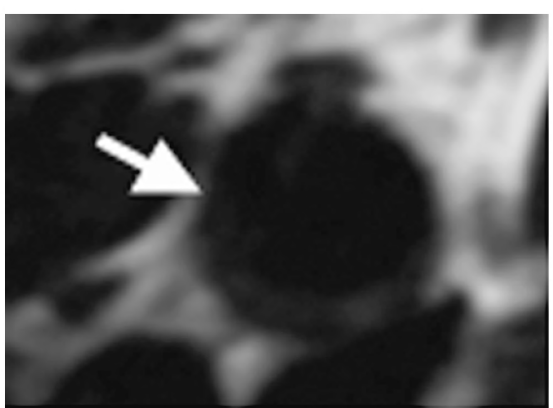

(E)

\section{Discussion}

Carotid atherosclerotic disease can lead to about $10 \%-25 \%$ of all ischemic cerebrovascular clinical manifestations such as TIA and stroke [10].

It has been discovered that plaque composition and morphology may predict the clinical behavior of the carotid atherosclerotic disease with subsequent risk of brain ischemic insult. The noninvasive imaging techniques as carotid ultrasound and ca-
Fig. (2): A 50 years old female patient, diabetic and hypertensive presented with loss of consciousness. (A) By carotid US duplex: Type 2: Predominantly $(>50 \%)$ hypoechoic with central echogenic foci, involving the right proximal ICA. (B, C, D, E) On carotid MRI, the plaque was isointense on the proton density image (arrow) (B), hypointense on T2-weighted image with associated small hyperintense component (C), and hyperintense on T1-weighted (D) and time-offlight (E). So, the MRI revealed it as a fatty plaque with a small hemorrhagic component. 
risk factor for further cerebrovascular ischemic insult.

In this preliminary inter method agreement study between the carotid ultrasound and the carotid MRI, a good agreement between the two examination $(\mathrm{x}=0.734)$ was concluded, as the carotid ultrasound examination correctly detected $88.1 \%$ of vulnerable plaque which was detected by the carotid MRI examination, a lower agreement was detected in study done by Reiter et al., [12] who compared the carotid plaques morphology diagnosed by the carotid ultrasound with the histopathological examination with $(\mathrm{ic}=0.52)$.

In the carotid ultrasound examination, 7 out of $29(24.1 \%)$ type 1 plaques were revealed in the carotid MRI study as lipid-rich plaque, and 20 out of 29 type 1 plaques (69\%) were hemorrhagic, while 2 out of $29(6.9 \%)$ were falsely diagnosed as fibrotic plaque. On the other hand, 3 out of 10 (30\%) type 2 plaques were diagnosed as lipid-rich plaque in the carotid MRI examination, and 7 out of $10(70 \%)$ were diagnosed as hemorrhagic plaque. Although the carotid ultrasound examination was able to characterize type I and II as vulnerable plaques, yet the carotid ultrasound can't confidently identify the lipid-rich plaque $(\mathrm{x}=0.087)$, while a moderate agreement between the ultrasound vulnerable plaque and the carotid MRI hemorrhagic plaque $(\mathrm{x}=0.536)$ was noted.

A study done by Chun et al., [13] which compared the histological morphology of carotid plaques after carotid endarterectomy with the preoperative carotid MRI examination, revealed that the overall accuracy of the carotid MRI was $95 \%$, with $85 \%$ sensitivity, and $92 \%$ specificity. There was good agreement between the carotid MRI and the histological findings concluding that MRI with multi-spectral analysis can identify the composition of the atherosclerotic plaques of the carotid artery in vivo with high sensitivity and specificity [13], another study done by Lukanova et al., [10] who had compared the composition of the carotid plaque using the carotid MRI versus the histological analysis also revealed a high diagnostic performance of the carotid MRI for detection of unstable carotid plaques with sensitivity of $100 \%$ and specificity of $88.8 \%$. They have considered that the noninvasive carotid MRI is the most accurate imaging for the evaluation of the morphology of the carotid plaque [10].

In addition to the assessment of the inter method agreement between the carotid ultrasound and the carotid MRI, our study also has evaluated the diagnostic performance of the carotid ultrasound gaining the benefit of considering the carotid MRI as the non-invasive gold stander modality for evaluation of the carotid plaque morphology.

In the carotid ultrasound examination, there were five false-negative cases which was falsely diagnosed as stable plaque depside that they were vulnerable plaques in the carotid MRI examination, as 3 out of $13(23.1 \%)$ of carotid MRI lipid-rich plaques was falsely diagnosed in the carotid ultrasound examination as type 3 or type 4 plaques, which was likely attributed to less echolucent texture of these plaques, yet 2 out of $29(6.9 \%)$ of the carotid MRI hemorrhagic plaques was falsely diagnosed as type 3 or type 4 plaque which was attributed to variable plaque texture during the evolution of plaque hemorrhage.

$88.1 \%$ of the MRI lipid and hemorrhagic vulnerable plaque was properly diagnosed as type 1 and 2 vulnerable plaques in the carotid ultrasound examination $(p=0.029)$. The sensitivity, specificity and accuracy of carotid ultrasound for characterization of vulnerable plaques was $88.1 \%, 88.8 \%$, and $88.3 \%$ respectively, near similar result was concluded by study done by Lukanova et al., [10] who compared the morphology of carotid plaque detected by carotid ultrasound with the histopathological results, and their study revealed that the carotid ultrasound sensitivity and specificity for diagnosing vulnerable plaques was $93.5 \%$ and 92.9\% respectively, yet a lower diagnostic performance of carotid ultrasound examination was concluded in studies done by Reiter et al., [12] and Watanabe et al., [14] as they revealed same sensitivity of $75 \%$ yet the specificity was $88 \%$ and $63 \%$ respectively, the different result seen in Reiter et al., [12] study may be attributed to the type of his study as he compared the B-flow imaging with the B-mode modality and didn't give a final decision about the advantages of one method over the another one.

Arai et al., [15] who compared the carotid ultrasound findings with the histopathological finding also revealed that the echogenic plaques found to be hard on pathology due to the high content of fibrous tissue and calcification.

No significant correlation was found in our study between the atherosclerotic risk factor and the age or sex, this was matched with Fabris et al., [16] who declared that there was a high prevalence of asymptomatic carotid atherosclerotic plaque in the general population. 
Our study revealed that patients with atherosclerotic risk factors including diabetes mellitus, dyslipidemia, and neurological deficits were more associated with vulnerable plaque composition with a highly significant value, this was concordant with the study done by Takaya et al., [17] who stated that the ultrasound echolucent vulnerable plaques was associated with higher risk of neurological manifestations and cerebrovascular events [17] . Similar significant correlation was also noted between the non-calcific plaques detected by the carotid MRI and the presence of various neurological manifestation, which was also concluded by studies performed by DeMarco et al., [18] and Zavodni et al., [19] as they stated that the cardiovascular insults were more common with the lipidrich and hemorrhagic vulnerable plaques.

The limitation of our study was the relatively small sample size and the unavailability of histopathological results of the carotid plaques. Further follow up after lipid-lowering therapy by comparing the carotid ultrasound result with the carotid MRI result may be of value to evaluate the changes in the plaque morphology.

\section{Conclusion:}

The low-cost bedside carotid ultrasound examination is considered the first-line imaging modality for the assessment of the composition of carotid plaque, with good agreement between the carotid ultrasound and the carotid MRI examinations and although the carotid MRI examination has higher diagnostic performance yet the carotid ultrasound has comparable results so it is the best imaging modalities for patients with cerebrovascular insult especially for unstable patients or those with contraindication for MRI. The high diagnostic performance of carotid ultrasound for discrimination of vulnerable plaques, in addition to the clinical evaluation of the cerebrovascular risk factors, will help to determine the risk of stroke and to decide the best further clinical management.

\section{References}

1- KERNAN W.N., OVBIAGELE B., BLACK H.R., et al.: Guidelines for the prevention of stroke in patients with stroke and transient ischemic attack: A guideline for healthcare professionals from the American Heart Association/American Stroke Association. Stroke, 45: 2160236, 2014.

2- DIELEMAN N., VAN DER KOLK A.G., ZWANENBURG J.J., et al.: Imaging intracranial vessel wall pathology with magnetic resonance imaging: Current prospects and future directions. Circulation, 130: 192-201, 2014.
3- SINGH N., MOODY A.R., GLADSTONE D.J., et al.: Moderate carotid artery stenosis: MR imaging depicted intraplaque hemorrhage predicts risk of cerebrovascular ischemic events in asymptomatic men. Radiology, 252: 502-8, 2009.

4- FLEG J.L., STONE G.W., FAYAD Z.A., et al.: Detection of high-risk atherosclerotic plaque: Report of the NHLBI Working Group on current status and future directions. JACC Cardiovasc Imaging, 5: 941-55, 2012.

5- SALEEM M.A., SADAT U., WALSH S.R., et al.: Role of carotid duplex imaging in carotid screening programmes-an overview. Cardiovasc. Ultrasound, 6: 34-7, 2008.

6- OPPENHEIM C., NAGGARA O., TOUZE E., et al.: Highresolution MR imaging of the cervical arterial wall: What the radiologist needs to know. Radiographics, 29: 141331, 2009.

7- CHOI Y.H., JUNG S.C. and LEE D.H.: Vessel Wall Imaging of the Intracranial and Cervical Carotid Arteries. Journal of Stroke, 17 (3): 238-55, 2015.

8- GEROULAKOS G., RAMASWAMI G., NICOLAIDES A., et al.: Characterization of symptomatic and asymptomatic carotid plaques using high resolution real-time ultrasonography. Br. J. Surg., 80: 1274-7, 1993.

9- CASADEI A., FLOREANI M., CATALINI R., et al.: Sonographichic characteristics of carotid artery plaques: Implications for follow-up planning? Ultrasound, 15 (3): 151-7, 2012.

10- LUKANOVA D.V., NIKOLOV N.K., GENOVA K.Z., et al.: The Accuracy of Noninvasive Imaging Techniques in Diagnosis of Carotid Plaque Morphology. Journal of Medical Science, 3 (2): 224-30, 2015.

11- FLEG J.L., STONE G.W., FAYAD Z.A., et al.: Detection of high-risk atherosclerotic plaque: Report of the NHLBI Working Group on current status and future directions. JACC Cardiovasc Imaging, 5: 941-55, 2012.

12- REITER M., HORVAT R., PUCHNER S., et al.: Plaque Imaging of the Internal Carotid Artery-Correlation of BFlow Imaging with Histopatology. AJNR Am. J. Neuroradiol., 28: 122-6, 2008.

13- CHUN Y., LEE M.M., MARINA S.F., et al.: In Vivo Accuracy of Multispectral Magnetic Resonance Imaging for Identifying Lipid-Rich Necrotic Cores and Intraplaque Hemorrhage in Advanced Human Carotid Plaques. Circulation, 104: 2051-6, 2001.

14- WATANABE Y., NAGAYAMA M., SUGA T., et al.: Characterization of atherosclerotic plaque of carotid arteries with histopathological correlation: Vascular wall MR imaging vs. color Doppler ultrasonography (US). J. Magn. Reson. Imaging, 28 (2): 478-85, 2008.

15- ARAI D., YAMAGUCHI S., MURAKAMI M., et al.: Characteristics of Carotid Plaque Findings on Ultrasonography and Black Blood Magnetic Resonance Imaging in Comparison with Pathological Findings, Trends in Neurovascular Surgery. Acta Neurochir. Suppl., 112: 15-9, 2011. 
16- FABRIS F., ZANOCCHI M., FONTE G., et al.: Carotid plaque, aging, and risk factors. A study of 457 subjects. Stroke, 25 (6): 1133-40, 1994.

17- TAKAYA N., YUAN C., CHU B., et al.: Association Between Carotid Plaque Characteristics and Subsequent Ischemic Cerebrovascular Events. A Prospective Assessment with MRI-Initial Results. Stroke, 37: 818-23, 2006.

18- DeMARCO J.K., OTA H., UNDERHILL H., et al.: MR Carotid Plaque Imaging and Contrast-Enhanced MR
Angiography Identifies Lesions Associated with Recent Ipsilateral Thromboembolic Symptoms: An In Vivo Study at 3T. American Journal of Neuroradiology, 31 (8): 1395402, 2010.

19- ZAVODNI A., WASSERMAN B., McCLELLEND R., et al.: Carotid Artery Plaque Morphology and Composition in Relation to Incident Cardiovascular Events: The MultiEthnic Study of Atherosclerosis (MESA). RSNA Radiology, 271 (2): 381-9, 2014.

\section{القيمة الإكلينيكية للموجات فوق الصوتية على الشرايين السباتية

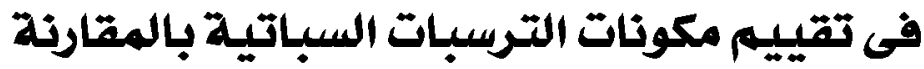

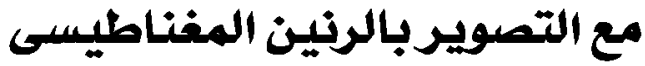

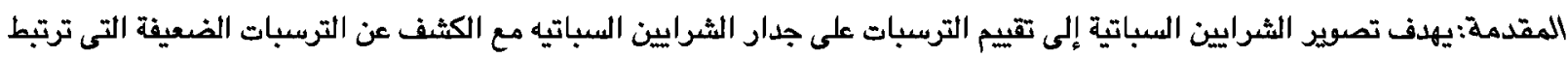
مع زيادة خطر الإصابة الدماغية، وبالتالى فإن التحديد الصحيع لمكونات التربسات يعتبر خطوة مهمة لمعالجة الإصابة الدماغية. الهدف من البحث: يهدف البحث إلى تحديد مقدار الإتفاق والمماثلة لفحص الشرايين السباتيه بين الموجات فوق الصوتية والتصوير بالرنين

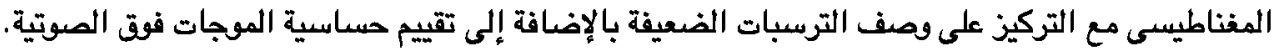

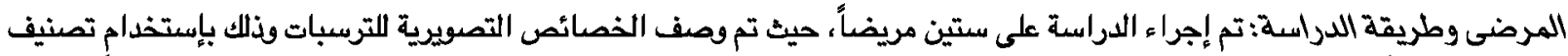
المعدل متبوعاً بتوصيف الترسبات بإستخدام التصوير بالرنين المغناطيسى، ومن ثم تم إجراء مقارنة النتائّ وتحليلها إحصائياً.

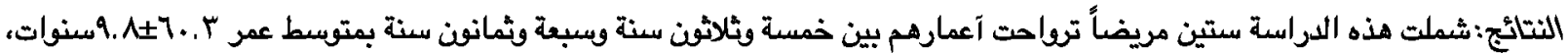

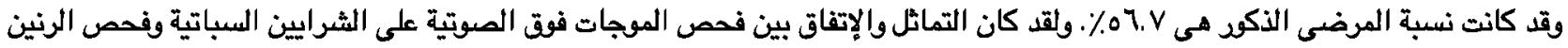

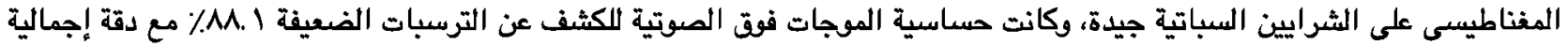

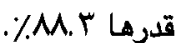

الخلاصة: يعتبر تصوير الشرايين السباتية بإستخدام الموجات فوق الصوتية هو الفحص الآولى لتقييم الترسبات على جدار الشرايين

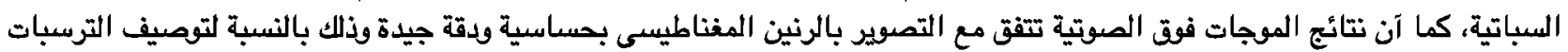

